\title{
Effect of a teaching programme on knowledge of postoperative pain management among nurses at Lagos University Teaching Hospital, Nigeria
}

\author{
M O Olawale, ${ }^{1} \mathrm{RN}, \mathrm{MSc} ; \mathrm{O}$ Olorunfemi, ${ }^{2} \mathrm{RN}, \mathrm{MSc} ; \mathrm{O}$ M Oyewole, ${ }^{1} \mathrm{RN}, \mathrm{MSc} ; \mathrm{R}$ A Salawu, ${ }^{3} \mathrm{RN}, \mathrm{PhD}$ \\ ${ }^{1}$ Department of Medical Surgical Nursing, School of Post Basic Nursing, Lagos University Teaching Hospital, Idi-Araba, Lagos State, Nigeria \\ ${ }^{2}$ Department of Medical Surgical Nursing, School of Nursing, University of Benin Teaching Hospital, Benin Edo State, Nigeria \\ ${ }^{3}$ Department of Medical Surgical Nursing, School of Nursing Sciences, Babcock University, Illisha Remo Ogun State, Nigeria
}

Corresponding author: O Olorunfemi (olaolorunfemi@yahoo.com)

\begin{abstract}
Background. Postoperative pain management is a way of reducing or eliminating pain and discomfort with minimum side-effects after surgery. Pain is a predictable and expected experience following surgery, and if not well controlled poses a major risk to the patient. Research shows that most patients suffer complications associated with postoperative pain. It is therefore important to develop approaches on how to improve knowledge of postoperative pain management among nurses.

Objective. To determine the effectiveness of a teaching programme on the knowledge of postoperative pain management among nurses in the adult surgical ward of Lagos University Teaching Hospital, Nigeria.

Methods. A quasi-experimental research design was conducted, and an accidental sampling technique used to select a total of 60 nurses. Probability sampling was used to divide this group into two ( $\operatorname{control} n=30$, experimental group $n=30$ ). Data were collected using a modified structured questionnaire, the 'Knowledge and attitudes survey regarding pain' tool. Ethical clearance was obtained from the hospital before the administration of the questionnaire. Data obtained were coded and analysed using Statistical Package for Social Sciences version 21.0 statistical software, at $p=0.05$ level of significance.

Results. The pre-intervention mean (standard deviation) score on knowledge of postoperative pain management among participants in the control group was $1.05(0.60)$ and $1.06(0.63)$ in the experimental group, with a mean difference of 0.01 . Following intervention, there was a rise in mean score on knowledge of postoperative pain management among the nurses in the experimental group to 1.62 (0.97), while participants in the control group had 1.05 (0.62), with a mean difference of 0.57 . There were significant statistical differences between the pre- and post-intervention mean score of participants' knowledge of postoperative pain management $(t=3.68, p=0.00)$.

Conclusion. The teaching programme was effective in improving participants' knowledge of postoperative pain management. Therefore continued education on postoperative pain management is recommended for nurses who are involved in the care of postoperative patients.
\end{abstract}

Afr J Health Professions Educ 2020;12(3):134-139. https://doi.org/10.7196/AJHPE.2020.v12i3.1343

Postoperative pain is a common, predictable and expected experience following surgery, and if not adequately managed leads to delayed postoperative recovery, poor prognosis, increased mortality and morbidity and increased risk for pain becoming chronic. ${ }^{[1]}$ This can lead to a decline in the patient's functionality and productivity, and consequently have a negative effect on their quality of life. ${ }^{[2]}$ The relief of pain has been and remains one of the major campaigns in the health sector, but regardless of this, studies continue to reveal poor and ineffective postoperative pain management by healthcare providers. ${ }^{[3]}$ This problem has been identified in underdeveloped, developing and developed countries: it is a global challenge. The Institute of Medicine in 2010 described quality in healthcare as 'the degree of healthcare provided to patient populations sufficient to improve their desired health outcomes. ${ }^{[4]}$ They identified six basic steps to high-quality healthcare: care must be effective; safe and reliable; patient-centred; efficient; timely; and equitable. Adequate pain management has consequently been described as: conducting a detailed clinical assessment of pain, periodically reassessing the patient's responses to pain treatment, and developing a modality of care that is safe, involves the patient and his or her family members and is culturally consistent and developmentally appropriate. ${ }^{[5]}$ Quality pain management training is important in ensuring effective patient care, and this can be achieved by empowering nurses with adequate knowledge and skills needed for the provision of quality postoperative pain management. ${ }^{[6]}$ The drive to improve postoperative pain management has been in place for some time, but nurses continue to experience challenges in this area of practice. ${ }^{[7]}$

Accreditation of healthcare organisations in 2000 specifically demands pain assessment and documentation, staff education in pain management and competency assessments, adequate pain control to allow functional rehabilitation, and education of patients and families on pain and symptom management. ${ }^{[7,8]}$ The fact, however, remains that most professions have neglected the concept of pain in their curriculum at undergraduate level and even during clinical practice. ${ }^{[9]}$ The reported undermanaged postoperative pain in different studies has affected institutions adversely, and contributes to decreased patient satisfaction and longer impaired mobility and hospital stay, increased morbidity and mortality and, consequently, poorer quality of life..$^{[10-12]}$

Poor management of postoperative acute pain can contribute to medical complications including pneumonia, deep vein thrombosis, infection and delayed healing, as well as the development of chronic pain. It is therefore important that all patients undergoing surgery should receive adequate pain management. However, evidence suggests this is not currently the case: between $10 \%$ and $50 \%$ of patients develop complications related to 
poor management of postoperative pain, even in developed countries. ${ }^{[13]}$ Inadequately managed pain can lead to adverse physical and psychological patient outcomes for individual patients and their families.

Consequently, this study aimed to determine the effectiveness of a teaching programme on the knowledge of postoperative pain management among nurses in the adult surgical ward of the Lagos University Teaching Hospital.

\section{Materials and methods}

The present study had a quasi-experimental design, and was conducted among nurses. The sample size was calculated using Leslie Kish's formula, where $\mathrm{n}_{0}=$ sample size, $p=$ the estimated proportion of an attribute, $\mathrm{q}=1-\mathrm{p}$, margin of error $=0.05$, with a confidence level of $95 \%$. Accidental sampling was used to select a sample size of 60 , and probability sampling was further used to divide the sample size into two equal parts (control and experimental group). The setting was Lagos University Teaching Hospital, (LUTH) situated in Idi-Araba, Mushin Local Government Area, Nigeria. The target population was nurses working in LUTH.

The inclusion criteria were as follows: nurses who were willing to participate in the study, and who consented after carefully going through the detailed procedure of bioethical principles in conducting research studies on human participants. Excluded were any nurses who had $<5$ years' working experience, and those working in the recovery room at the time of the research, to avoid distractions from taking care of the critical ill patients in their care. A modified structured questionnaire called the Knowledge and Attitudes Survey regarding Pain Tool (KASPT) was used to evaluate the effect of a teaching programme on the knowledge of postoperative pain management among nurses. The data-gathering tools were the demographic characteristic questionnaire, a questionnaire on the knowledge of pain assessment, knowledge of pain management and knowledge on the route and method of postoperative drug administration. The KASPT is a global standardised tool that was designed and reported by Alqahtani et al. ${ }^{[14]}$ in 2019. The psychometric properties of the questionnaire were checked by an expert in the field using face and content validity criteria, and the reliability of the instrument was established through a pretest method by administering 15 questionnaires to nurses with the same inclusion criteria among nurses in the Federal Medical Centre, Ebute-Meta, Lagos. Cronbach's a coefficient was used to test reliability. The value obtained was 0.8 , which indicated high reliability of the instrument.

There were three phases in this study. Phase 1 was mobilisation. In this phase, the researchers met with the director of the nursing service, the head of the department and staff nurses in the adult surgical ward in LUTH to explain the purpose of the study and its benefits. The purpose of this was also to seek co-operation for the success of the study. The researchers and research assistants visited the ward on Monday to Friday in the mobilisation week of the study to observe how the staff managed postoperative pain, and gaps were identified that were used to modify the training programme (see appendix: www.http://ajhpe.org.za/public/ files/1343.pdf). Interested participants were selected for the study after seeking their consent. Questionnaires were administered as a pretest to both control and experimental groups. The results from this phase were also used to modify the training programme. Experimental and control participants were followed up via phone calls (at least a call per week for the period of the training) and text messages, reminding them to come for the training. Phase 2 consisted of class-based training about postoperative pain management, and was developed and presented over 3 weeks in a seminar room. In the first week of the training, 10, 5, 4, 6 and 5 participants were available on different weekdays, respectively, based on their shifts. Throughout the training programme, the researchers used teaching aids. Weeks 2 and 3 of follow-up produced good results. During phase 3, after the application of the training programme for the experimental group, a post-test was conducted, using the same questionnaire as for the pre-test for experimental and control groups. Data obtained were coded and analysed using Statistical Package for Social Sciences (SPSS) version 21.00 statistical software (IBM Corp., USA). Variables and research questions were analysed using descriptive statistics and independent $t$-tests for inferential statistics.

\section{Ethical considerations}

Ethical approval for this study was obtained from two institutional ethical committees where the study took place, with approval ref. no. BUHREC576/16 on 30 November 2016 from Babcock University, and ref. no. ADM/DCST/ HREC/APP1398 from LUTH on 5 January 2017. The interviewer explained the importance of the study and what the participants and others stood to benefit from it. Therefore, informed consent was obtained from the participants before the study commenced. Participation in the study was voluntary, and participants had the right to withdraw from the study at any stage.

\section{Results}

Table 1 shows that $33.3 \%$ of the respondents in the control group were between the ages of 31 and 40 and 41 and 50 years, while 16.7\% were between 21 and 30 and 51 years and above, with mean ages of 42.5 and 40.0 , respectively. All respondents (100\%) were female. With regard to their educational status, $56.7 \%$ were registered nurses and midwives (RN/ RM), $40 \%$ were bachelor degree holders while $3.3 \%$ had master's degrees. Concerning their professional status, $23.3 \%$ were classed nurse officer 2 (NOII) and senior nurse officer (SNO), while $13.3 \%$ were nurse officer 1 (NOI), principal nurse officer (PNO), acting chief nurse officer (ACNO) and chief nursing officer $(\mathrm{CNO})$. Forty percent of respondents had $<5$ years' working experience, $23.3 \%$ had 6 - 10 years' experience, $6.7 \%$ had $11-15$ years, $13.3 \%$ had $16-20$ years and $16.7 \%$ had 20 years' experience. In the experimental group, $36.7 \%$ of respondents were between ages 21 and 30 , $30 \%$ were between 31 and 40 , while $16.7 \%$ were between 41 and 50 and 51 and 60 years. A total of $96.7 \%$ were female, and $3.3 \%$ male. With regard to their educational status, $30 \%$ were $\mathrm{RN}, 46.7 \%$ were $\mathrm{RN} / \mathrm{RM}$ and $23.7 \%$ had a BSc degree. Concerning their professional status, $30 \%$ were NOII, $36.7 \%$ were NOI, $10 \%$ were SNO and $23 \%$ were CNO. Fifty percent of the respondents had $>5$ years' working experience, $13.3 \%$ had $6-10$ years' experience, $3.3 \%$ had 11 - 15 years, and $33.3 \%$ had 20 years' experience.

Table 2 shows that all respondents (100\%) knew that reassessment of pain after medication helps to evaluate the effectiveness of the pain medication. In the experimental group, only $13.3 \%$ knew that patients can sleep in spite of severe pain, 50\% knew that analgesics should be given round the clock on a fixed schedule and $40 \%$ knew that transcutaneous electrical nerve stimulation (TENS) can be used as an adjunct to other postoperative pain treatments. In the control group, $96.7 \%$ agreed that reassessment of pain after medication helps to evaluate the effectiveness of the medication, $10 \%$ knew that patients can sleep in spite of severe pain, only $30 \%$ knew that analgesics should be given round the clock on a fixed schedule and $46.7 \%$ agreed that TENS could be used as an adjunct to other postoperative pain treatments. Overall, there was no difference in knowledge mean (standard deviation (SD)) scores 
Table 1. Sociodemographic characteristics of respondents in each group

\begin{tabular}{|c|c|c|}
\hline Variable & $\begin{array}{l}\text { Experimental } \\
(N=30), n(\%)\end{array}$ & $\begin{array}{l}\text { Control } \\
(N=30), n(\%)\end{array}$ \\
\hline \multicolumn{3}{|l|}{ Age, years } \\
\hline $21-30$ & $11(36.7)$ & $5(16.7)$ \\
\hline $31-40$ & $9(30.0)$ & $10(33.3)$ \\
\hline $41-50$ & $5(16.7)$ & $10(33.3)$ \\
\hline $51-60$ & $5(16.7)$ & $5(16.7)$ \\
\hline Mean & 40.0 & 42.5 \\
\hline \multicolumn{3}{|l|}{ Gender } \\
\hline Male & $1(3.3)$ & 0 \\
\hline Female & $29(96.7)$ & $30(100.0)$ \\
\hline \multicolumn{3}{|l|}{ Education } \\
\hline RN & $9(30.0)$ & 0 \\
\hline $\mathrm{RN} / \mathrm{RM}$ & $14(46.7)$ & $17(56.7)$ \\
\hline Bachelor's degree & $7(23.3)$ & $12(40.0)$ \\
\hline Master’s degree & 0 & $1(3.3)$ \\
\hline \multicolumn{3}{|l|}{ Professional status } \\
\hline NOII & $9(30.0)$ & $7(23.3)$ \\
\hline NOI & $11(36.7)$ & $4(13.3)$ \\
\hline SNO & $3(10.0)$ & $7(23.3)$ \\
\hline $\mathrm{PNO}$ & 0 & $4(13.3)$ \\
\hline $\mathrm{ACNO}$ & 0 & $4(13.3)$ \\
\hline $\mathrm{CNO}$ & $7(23.3)$ & $4(13.3)$ \\
\hline \multicolumn{3}{|c|}{ Work experience, years } \\
\hline $5-<6$ & $15(50.0)$ & $12(40.0)$ \\
\hline $6-10$ & $4(13.3)$ & $7(23.3)$ \\
\hline $11-15$ & $1(3.3)$ & $2(6.7)$ \\
\hline $16-20$ & 0 & $4(13.3)$ \\
\hline$\geq 20$ & $10(33.3)$ & $5(16.7)$ \\
\hline
\end{tabular}

between the two groups before intervention: $1.06(0.63)$ and $1.05(0.60)$, respectively.

Table 3 shows the post-intervention knowledge level of nurses in both groups after the teaching programme. Responses to questions on knowledge about postoperative pain assessment and management after the intervention showed that there was improvement in knowledge in the experimental group: the majority (70\%) knew that patients can sleep in spite of severe pain, compared with $13.3 \%$ pre intervention; $86.7 \%$ knew that analgesics should be given round the clock on a fixed schedule, while $90 \%$ knew that TENS can be used as an adjunct to other postoperative pain treatments. In the control group, there was no significant improvement in knowledge: $10 \%$ agreed that patients can sleep in spite of severe pain pre and post intervention, 36.7\% knew that analgesics should be given round the clock on a fixed schedule while $50 \%$ knew that TENS can be used as an adjunct to other postoperative pain treatments.

In Table 4, the $p$-value of 0.00 reveals that there was a significant difference between the knowledge of the control and experimental groups after the intervention.

\section{Discussion}

Knowledge plays a major role in decision-making, because to be well informed in nursing practice is to be knowledgeable about different skills required to enhance the recovery of patient. ${ }^{[15]}$ The findings from this study revealed overall fair knowledge about postoperative pain management among the nurses. In 2019, Tinaikar and Anuradha ${ }^{[16]}$ carried out a crosssectional study on nursing staff working in a tertiary hospital attached to KRIMS, India, for a period of 2 months. An adapted version of the Knowledge and Attitudes Survey Regarding Pain (KASRP) instrument was used to test the knowledge of nurses, and found that $64 \%$ nurses had adequate knowledge on postoperative pain management, but suggested that the knowledge level need to be improved upon. ${ }^{[16]}$ In the same year, a study ${ }^{[17]}$ was carried out on nurses' knowledge regarding postoperative pain management in a hospital in Peshawar, Pakistan. The study included nurses working at the bedside in postoperative units of the hospital. A selfdeveloped questionnaire was used for data collection. The $\chi^{2}$ test was used to analyse the data, and it was found that the level of knowledge could be divided into poor, average, good and excellent categories. Percentage scores in these categories were: poor (0\%); average (6.7\%); good (71.7\%); and excellent (21.7\%). ${ }^{[17]}$ These two studies are in agreement with the fact that there is overall fairly good knowledge among nurses about postoperative pain management, but an ideal situation is yet to be achieved.

In addition, the present study showed that there was a relationship between the teaching programme and the knowledge of pain assessment. This is in agreement with the results of Keshk et al.$^{[18]}$ in 2018, who carried out a study on the effectiveness of an educational programme regarding nursing on acquiring advanced skills among internship nursing students, and found that there was a statistically significant level of knowledge among the internship nursing students regarding steps in nursing assessment after the educational programme implementation, compared with an unsatisfactory level before the implementation of the educational programme. ${ }^{[18]}$

The present study also showed that there was a relationship between the teaching programme and the knowledge of postoperative pain management. This is in agreement with a study on the role of patient education in postoperative pain management. ${ }^{[19]}$ The authors found that postoperative pain continues to be a significant issue in healthcare, with a considerable proportion of patients experiencing severe pain after surgery and finding pain management at home challenging. There are several barriers to effective pain management involving both patients and healthcare professionals, and the authors concluded that patient education is a useful way to overcome many of these barriers involved in postoperative pain management. ${ }^{[18]}$

In 2019 a study was carried out in a government hospital in the United Arab Emirates between February and April 2019 on the effect of a nursing in-service education programme on nurses' knowledge and attitudes towards pain management. The sample of this study consisted of 200 participants selected randomly, who were exposed to a pre-test and posttest before and after receiving the pain management programme, and the findings on the experimental group revealed that the mean (SD) score on the KASRP increased after the intervention from 61.36 (11.60) to 69.94 (7.74), with a mean difference of 8.58 , while in the control group the mean score slightly decreased following the test $(60.99$ (1.53)) compared with the pre-test $(61.00(11.60))$, with a mean difference of 0.01 . The in-service education pain management programme therefore proved to be effective. ${ }^{[20]}$

This present study also revealed that there was a relationship between the teaching programme and the knowledge of route and other skills required for the administration of postoperative pain drugs. This substantiates a study ${ }^{[21]}$ carried out on 150 undergraduate medical students of Gandhi Medical College, India, for a period of 3 months, which found that of 136 students, $93.4 \%$ had seen intramuscular (IM) or intravenous (IV) 
Table 2. Pre-intervention knowledge level of nurses in each group

\begin{tabular}{|c|c|c|c|c|}
\hline \multirow[b]{2}{*}{ Item } & \multicolumn{2}{|c|}{ Experimental } & \multicolumn{2}{|c|}{ Control } \\
\hline & $(N=30), n(\%)$ & Mean (SD) & $(N=30), n(\%)$ & Mean (SD) \\
\hline \multicolumn{5}{|l|}{ A. Knowledge of pain assessment before intervention } \\
\hline Ever heard of multimodal analgesia? & $6(20.00)$ & $0.4(0.23)$ & $9(30.00)$ & $0.6(0.35)$ \\
\hline Received training on postoperative pain assessment and management? & $10(33.30)$ & $0.7(0.39)$ & $9(30.00)$ & $0.6(0.35)$ \\
\hline $\begin{array}{l}\text { Reassessment of pain after medication helps to evaluate the effectiveness of pain } \\
\text { medication }\end{array}$ & $30(100.00)$ & $2.0(1.17)$ & $29(96.70)$ & $1.9(1.13)$ \\
\hline Postoperative pain assessments should be done as often as vital signs are taken & $27(90.00)$ & $1.8(1.05)$ & $26(86.70)$ & $1.7(0.99)$ \\
\hline \multicolumn{5}{|l|}{ Pain assessment scales include: } \\
\hline Numeric rating scale & $25(83.30)$ & $1.7(0.97)$ & $9(30.00)$ & $0.6(0.35)$ \\
\hline Visual analogue scale & $14(46.70)$ & $0.9(0.55)$ & $14(46.70)$ & $0.9(0.55)$ \\
\hline Wong Baker faces scale & $9(30.00)$ & $0.6(0.35)$ & $6(20.00)$ & $0.4(0.23)$ \\
\hline Verbal rating scale & $20(66.70)$ & $1.3(0.78)$ & $17(56.70)$ & $1.1(0.66)$ \\
\hline McGill pain questionnaire & $11(36.70)$ & $0.7(0.43)$ & $6(20.00)$ & $0.4(0.23)$ \\
\hline A numerical rating scale & $5(16.70)$ & $0.3(0.19)$ & $5(16.7)$ & $0.3(0.19)$ \\
\hline The most accurate judge of the intensity of pain is the patient & $25(83.30)$ & $1.7(0.97)$ & $23(76.7)$ & $1.5(0.89)$ \\
\hline \multicolumn{5}{|l|}{ B. Knowledge of pain management before intervention } \\
\hline Patients should be individually assessed to determine cultural influences on pain & $26(86.70)$ & $1.7(1.01)$ & $24(80)$ & $1.6(0.94)$ \\
\hline $\begin{array}{l}\text { In applying the principles of pain treatment, the client must be believed about } \\
\text { perceptions of own pain }\end{array}$ & $29(96.70)$ & $1.9(0.60)$ & $28(93.3)$ & $1.9(1.09)$ \\
\hline Patients who can be distracted from pain usually do not have severe pain & $12(40.00)$ & $0.8(0.47)$ & $19(63.3)$ & $0.6(0.37)$ \\
\hline Patients may sleep in spite of severe pain & $4(13.30)$ & $0.3(0.16)$ & $3(10.00)$ & $0.2(0.11)$ \\
\hline $\begin{array}{l}\text { Giving patients sterile water by injection (placebo) is a useful test to determine if the } \\
\text { pain is real }\end{array}$ & $5(16.70)$ & $0.3(0.17)$ & $7(23.30)$ & $0.5(0.27)$ \\
\hline Patients should be encouraged to endure as much pain as possible before using an opioid & $18(60.00)$ & $1.2(0.70)$ & $15(50.00)$ & $1.0(0.58)$ \\
\hline Patients' spiritual beliefs may lead them to think pain and suffering are necessary & $9(30.00)$ & $0.6(0.35)$ & $18(60.00)$ & $1.2(0.70)$ \\
\hline \multicolumn{5}{|l|}{ Assessment of patient's pain postoperatively is best done by: } \\
\hline Asking the patient to trace the area of pain & $17(56.70)$ & $1.1(0.66)$ & $15(50.00)$ & $1.0(0.58)$ \\
\hline Asking the patient to describe how (s)he feels the pain & $24(80.00)$ & $1.6(0.94)$ & $30(100.00)$ & $2.0(1.17)$ \\
\hline Checking patient's pulse & $15(50.00)$ & $1.0(0.59)$ & $16(53.30)$ & $1.1(0.62)$ \\
\hline Checking blood pressure & $16(53.30)$ & $1.0(0.62)$ & $16(53.30)$ & $1.0(0.62)$ \\
\hline Using an objective pain-assessment tool & $23(76.70)$ & $1.5(0.89)$ & $16(53.30)$ & $1.1(0.62)$ \\
\hline \multicolumn{5}{|l|}{ The goal of giving narcotic analgesics during the first 48 hours postoperatively is to: } \\
\hline Relieve pain completely & $4(13.30)$ & $0.3(0.16)$ & $4(13.30)$ & $0.3(0.16)$ \\
\hline Relieve as much pain as possible & $26(86.70)$ & $1.7(1.01)$ & $26(86.7)$ & $1.7(1.01)$ \\
\hline \multicolumn{5}{|c|}{ C. Knowledge on route and other skills required for the administration of postoperative pain drug before intervention } \\
\hline Intravenous & $19(63.30)$ & $1.3(0.74)$ & $27(90.00)$ & $1.8(1.05)$ \\
\hline Intramuscular & $11(36.70)$ & $0.7(0.43)$ & $3(10.00)$ & $0.2(0.12)$ \\
\hline Around the clock on a fixed schedule & $15(50.00)$ & $1.0(0.58$ & $9(30.00)$ & $0.6(0.35)$ \\
\hline Only when the patient asks for it & $3(10.00)$ & $0.2(0.12)$ & $3(10.00)$ & $0.2(0.12)$ \\
\hline Only when the nurse determines that the patient has moderate or greater discomfort & $2(6.70)$ & $0.1(0.08)$ & $1(3.30)$ & $0.1(0.04)$ \\
\hline Only as ordered by the surgery resident & $10(33.30)$ & $0.7(0.39)$ & $17(56.70)$ & $1.1(0.66)$ \\
\hline $\begin{array}{l}\text { Combining analgesics that work by different mechanisms (e.g. combining an NSAID } \\
\text { with an opioid) may result in better pain control with fewer side-effects than using a } \\
\text { single analgesic agent }\end{array}$ & $27(90.00)$ & $1.8(1.05)$ & $19(63.30)$ & $1.3(0.74)$ \\
\hline $\begin{array}{l}\text { Oral route is preferred for administration of daily analgesics (if all body systems are } \\
\text { functional) }\end{array}$ & $27(90.00)$ & $1.8(1.05)$ & $14(46.70)$ & $0.9(0.55)$ \\
\hline Unrelieved pain has harmful effects on patient's respiratory function and activity level & $22(73.30)$ & $1.5(0.86)$ & $23(76.70)$ & $1.5(0.90)$ \\
\hline TENS can be used as an adjunct to other postoperative pain treatments & $12(40.00)$ & $0.8(0.47)$ & $14(46.70)$ & $0.9(0.55)$ \\
\hline Postoperative pain management starts from the pre-operative phase & $24(80.00)$ & $1.6(0.94)$ & $22(73.30)$ & $1.5(0.86)$ \\
\hline Deep breathing causes relaxation and thus relieves pain & $28(93.30)$ & $1.9(1.09)$ & $27(90.00)$ & $1.8(1.05)$ \\
\hline Positioning is effective in the management of postoperative pain & $23(76.70)$ & $1.5(0.90)$ & $25(83.30)$ & $1.7(0.97$ \\
\hline Distraction (e.g. music) is not an effective measure in the management of postoperative pain & $9(30.00)$ & $0.6(0.35)$ & $17(56.70)$ & $1.1(0.66)$ \\
\hline Non-pharmacological measures of pain management can replace pharmacological measures & $14(46.70)$ & $0.9(0.55)$ & $17(56.7)$ & $1.1(0.66)$ \\
\hline Ground mean & & $1.06(0.63)$ & & $1.05(0.60)$ \\
\hline
\end{tabular}


Table 3. Post-intervention knowledge level of nurses in each group

\begin{tabular}{|c|c|c|c|c|}
\hline & \multicolumn{2}{|c|}{ Experimental } & \multicolumn{2}{|c|}{ Control } \\
\hline & $(N=30), n(\%)$ & Mean (SD) & $(N=30), n(\%)$ & Mean (SD) \\
\hline \multicolumn{5}{|l|}{ A. Knowledge of pain assessment after intervention } \\
\hline Ever heard of multimodal analgesia? & $29(96.70)$ & $1.9(1.13)$ & $9(30.00)$ & $0.6(0.32$ \\
\hline Received training on postoperative pain assessment and management? & $26(86.70)$ & $1.7(0.99)$ & $10(33.30)$ & $0.7(0.39)$ \\
\hline $\begin{array}{l}\text { Reassessment of pain after medication helps to evaluate the effectiveness of pain } \\
\text { medication }\end{array}$ & $30(100.0)$ & $2.0(1.17)$ & $28(93.30)$ & $1.9(1.09)$ \\
\hline Postoperative pain assessments should be done as often as vital signs are taken & $30(100.0)$ & $2.0(1.17)$ & $26(86.70)$ & $1.7(0.99)$ \\
\hline \multicolumn{5}{|l|}{ Pain assessment scales include: } \\
\hline Numeric rating scale & $30(100.0)$ & $2.0(1.17)$ & $10(33.30)$ & $0.7(0.39)$ \\
\hline Visual analogue scale & $25(83.30)$ & $1.7(0.97)$ & $15(50.00)$ & $1.0(0.59)$ \\
\hline Wong Baker faces scale & $23(76.70)$ & $1.5(0.89)$ & $6(20.00)$ & $0.4(0.23)$ \\
\hline Verbal rating scale & $21(70.00)$ & $1.4(0.81)$ & $18(60.00)$ & $1.2(0.70)$ \\
\hline McGill pain questionnaire & $14(46.70)$ & $0.9(0.55)$ & $7(23.30)$ & $0.4(0.27)$ \\
\hline A numerical rating scale & $17(56.7)$ & $1.1(0.66)$ & $5(16.70)$ & $0.3(0.19)$ \\
\hline The most accurate judge of the intensity of pain is the patient & $30(100.0)$ & $2.0(1.17)$ & $24(80.00)$ & $1.6(0.94)$ \\
\hline \multicolumn{5}{|l|}{ B. Knowledge of pain management after intervention } \\
\hline Patients should be individually assessed to determine cultural influences on pain & $30(100.0)$ & $2.0(1.17)$ & $25(83.30)$ & $1.7(0.97)$ \\
\hline $\begin{array}{l}\text { In applying the principles of pain treatment, the client must be believed about } \\
\text { perceptions of own pain }\end{array}$ & $30(100.0)$ & $2.0(1.17)$ & $28(93.30)$ & 1.9 (1.09) \\
\hline Patients who can be distracted from pain usually do not have severe pain & $26(86.70)$ & $1.7(0.99)$ & $21(70.00)$ & $1.4(0.81)$ \\
\hline Patients may sleep in spite of severe pain & $21(70.00)$ & $1.4(0.81)$ & $5(16.70)$ & $0.3(0.19)$ \\
\hline $\begin{array}{l}\text { Giving patients sterile water by injection (placebo) is a useful test to determine if the } \\
\text { pain is real }\end{array}$ & $25(83.30)$ & $1.7(0.97)$ & $8(26.70)$ & $0.5(0.31)$ \\
\hline Patients should be encouraged to endure as much pain as possible before using an opioid & $27(90.00)$ & $1.5(1.05)$ & $14(46.70)$ & $0.9(0.55)$ \\
\hline Patients' spiritual beliefs may lead them to think pain and suffering are necessary & $15(50.00)$ & $1.0(0.59)$ & $18(60.00)$ & $1.2(0.70)$ \\
\hline \multicolumn{5}{|l|}{ Assessment of patient's pain postoperatively is best done by: } \\
\hline Asking the patient to trace the area of pain & $21(70.00)$ & $1.4(0.81)$ & $15(50.00)$ & $1.0(0.59)$ \\
\hline Asking the patient to describe how (s)he feels the pain & $30(100.0)$ & $2.0(1.17)$ & $30(100.0)$ & $2.0(1.17)$ \\
\hline Checking patient's pulse & $21(70.00)$ & $1.4(0.81)$ & $17(56.7)$ & $1.1(0.66)$ \\
\hline Checking blood pressure & $18(60.00)$ & $1.2(0.70)$ & $16(53.30)$ & $1.0(0.62)$ \\
\hline Using an objective pain-assessment tool & $26(86.70)$ & $1.7(0.99)$ & $17(56.7)$ & $1.1(0.66)$ \\
\hline \multicolumn{5}{|l|}{ The goal of giving narcotic analgesics during the first 48 hours postoperatively is to: } \\
\hline Relieve pain completely & $21(70.00)$ & $1.4(0.81)$ & $5(16.70)$ & $0.3(0.19)$ \\
\hline Relieve as much pain as possible & $29(96.67)$ & $1.9(1.13)$ & $25(83.33)$ & $1.7(0.97)$ \\
\hline \multicolumn{5}{|c|}{ C. Knowledge on route and other skills required for the administration of postoperative pain drug after intervention } \\
\hline Intravenous & $29(96.67)$ & $1.9(1.13)$ & $27(90.00)$ & $1.5(1.05)$ \\
\hline Intramuscular & $30(100.0)$ & $2.0(1.17)$ & $6(20.00)$ & $0.4(0.23)$ \\
\hline Around the clock on a fixed schedule & $26(86.70)$ & $1.7(0.99)$ & $10(33.30)$ & $0.7(0.39)$ \\
\hline Only when the patient asks for it & $16(53.30)$ & $1.0(0.62)$ & $7(23.30)$ & $0.4(0.27)$ \\
\hline Only when the nurse determines that the patient has moderate or greater discomfort & $18(60.00)$ & $1.2(0.70)$ & $5(16.70)$ & $0.3(0.19)$ \\
\hline Only as ordered by the surgery resident rather than using a single analgesic agent & $27(90.00)$ & $1.5(1.05)$ & $20(66.70)$ & $1.3(0.78)$ \\
\hline $\begin{array}{l}\text { Oral route is preferred for administration of daily analgesics (if all body systems are } \\
\text { functional) }\end{array}$ & $30(100.0)$ & $2.0(1.17)$ & $15(50.00)$ & $1.0(0.59)$ \\
\hline Unrelieved pain has harmful effects on patient's respiratory function and activity level & $30(100.0)$ & $2.0(1.17)$ & $15(50.00)$ & $1.0(0.59)$ \\
\hline TENS can be used as an adjunct to other postoperative pain treatments & $27(90.00)$ & $1.5(1.05)$ & $21(70.00)$ & $1.4(0.81)$ \\
\hline Postoperative pain management starts from the pre-operative phase & $29(96.67)$ & $1.9(1.13)$ & $26(86.70)$ & $1.7(0.99)$ \\
\hline Deep breathing causes relaxation and thus relieves pain & $27(90.00)$ & $1.5(1.05)$ & $17(56.7)$ & $17(56.7)$ \\
\hline Positioning is effective in the management of postoperative pain & $26(86.70)$ & $1.7(0.99)$ & $18(60.00)$ & $1.2(0.70)$ \\
\hline Distraction (e.g. music) is not an effective measure in the management of postoperative pain & $29(96.67)$ & $1.9(1.13)$ & $18(60.00)$ & $1.2(0.70)$ \\
\hline Non-pharmacological measures of pain management can replace pharmacological & $11(36.70)$ & $0.7(0.43)$ & $17(56.7)$ & $17(56.7)$ \\
\hline Ground mean & & $1.6(0.97)$ & & $1.05(0.62)$ \\
\hline
\end{tabular}


Table 4. $t$-test analysis for the effectiveness of the teaching programme on knowledge of postoperative pain management among nurses in the experimental group

\begin{tabular}{ll}
\hline Knowledge & $\boldsymbol{n}(\%)$ \\
\hline Pre-test & \\
Poor & $3(10.0)$ \\
Average & $19(63.3)$ \\
Good & $8(26.7)$ \\
Post-test & \\
Poor & - \\
Average & $8(26.7)$ \\
Good & $22(73.3)$ \\
&
\end{tabular}

$\mathrm{SD}=$ standard deviation.

administration, but only $29.4 \%$ and $16.9 \%$ had ever administered IM and IV injections, respectively. A significant increase in knowledge regarding IM and IV administration technique was observed following interventional training of the participants. ${ }^{[21]}$

Finally, some limitations were encountered in the course of the study despite the research objective having been met. Gathering all the nurses into a single session for the training programme was difficult because of their different shifts, hence the participants were trained in several different sessions, which may have affected the results.

\section{Conclusion}

The results of this study reveal that there is a fair knowledge level among nurses in the areas of postoperative pain, and pharmacological and nonpharmacological measures of pain management. The results also showed that a teaching programme was useful in improving nurses' knowledge of postoperative pain management, which may further improve the practice of pain management, and patients' satisfaction levels. The findings of this study, therefore, create an impetus for continued education of nurses taking care of patients after surgery.

Declaration. The present article was derived from the result of thesis no. BUHREC608/16 that was approved by the research ethics committee of Babcock University, Illishan-Remo, Ogun State, Nigeria.

Acknowledgements. The researchers would like to thank the nurses who participated in the study from LUTH, despite their tight schedules. Author contributions. All authors contributed equally to the research.

Funding. None.

Conflicts of interest. None.

1. Feldheiser A, Aziz O, Baldini G, et al. Enhanced Recovery After Surgery (ERAS) for gastrointestinal surger part 2: Consensus statement for anaesthesia practice. Acta Anaesthesiol Scand 2016;60(3):289-334. https://doi org/10.1111/aas.1265
2. Younossi ZM, Stepanova M, Afdhal N, et al. Improvement of health-related quality of life and work productivity in chronic hepatitis $\mathrm{C}$ patients with early and advanced fibrosis treated with ledipasvir and sofosbuvir. J Hepato 2015;63(2):337-345. https://doi.org/10.1016/j.j.hep.2015.03.014

3. Rawal N. Current issues in postoperative pain management. Eur J Anaesthesiol 2016;33(3):160-171. https://doi. org/10.1097/EJA.0000000000000366

4. Nass S, Beaupin LK, Demark-Wahnefried W, et al. Identifying and addressing the needs of adolescents and young adults with cancer: Summary of an Institute of Medicine workshop. Oncologist 2015;20(2):186. https://doi. young adults with cancer: Summary of

scrol

Scarborough BM, Smith CB. Optimal pain management for pati
Clin 2018;68(3):182-196. https:///oi.org/10.3322\%2Fcaac.21453 6. Menlah A, Garti I, Amoo SA, Atakro CA, Amponsah C, Agyare DF. Knowledge, attitudes, and practices of postoperative pain management by nurses in selected district hospitals in Ghana. SAGE Open Nurs 2018;4(2018) https://doi.org/10.1177/2377960818790383

7. Meissner W, Coluzzi F, Fletcher D, et al. Improving the management of postoperative acute pain: Priorities fo change. Curr Med Res Opin 2015;31(11):2131-2143. https://doi.org/10.1185/03007995.2015.1092122

. Hui D, Bruera E. Integrating palliative care into the trajectory of cancer care. Nat Rev Clin Oncol 2016;13(3):159. https://doi.org/10.1038\%2Fnrclinonc.2015.201

9. Knaul FM, Farmer PE, Krakauer EL, et al. Alleviating the access abyss in palliative care and pain relief - an imperative of universal health coverage: The Lancet Commission report. Lancet 2018;391(10128):1391-1454. https://doi.org/10.1016/s0140-6736(17)32513-8

10. Cullom C, Weed JT. Anesthetic and analgesic management for outpatient knee arthroplasty. Curr Pain Headache Rep 2017;21(5):23. https://doi.org/10.1007/s11916-017-0623-y

11. Bird JM, Owen RG, D'Sa S, et al. Guidelines for the diagnosis and management of multiple myeloma 2011. Br J Haematol 2011;154(1):32-75. https://doi.org/10.1111/j.1365-2141.2011.08573.x

12. Allen J, Hutchinson AM, Brown R, Livingston PM. Quality care outcomes following transitional care intervention for older people from hospital to home: A systematic review. BMC Health Serv Res 2014;14(1):346. https://doi for older people from hospital

13. Meissner W, Coluzzi F, Fletcher D, et al. Improving the management of postoperative acute pain: Priorities for change. Curr Med Res Opin 2015;31(11):2131-2143. https://doi,org/10.1185/03007995.2015.1092122

14. Alqahtani M, Jones LK. Quantitative study of oncology nurses' knowledge and attitudes towards pain management in Saudi Arabian hospitals. Eur J Oncol Nurs 2015;19(1):44-49. https://doi.org/10.1016/j.ejon.2014.07.013

15. Osian EA, Afemikhe JA, Olorunfemi O, Eweka A. Knowledge and perception of assisted reproductive technology among women attending the University of Benin Teaching Hospital, Benin City, Nigeria, 2018. J Nurs Midwifery S 2019;6:125-130. https://doi.org/10.4103/JNMS.JNMS_15_19

16. Tinaikar A, Anuradha G. Knowledge of postoperative pain management among nurses in a tertiary hospital Uttar Kannada, Karnataka. Inter J Surg 2019;3(4):445-447. https://doi.org/10.33545/surgery.2019.v3.i4h.282

17. Zeb A, Farhana J, Marym U, Bi NB. Nurses' knowledge regarding postoperative pain management. J Healthcare Commun 2019;4(1):1654. https://doi.org/10.4172/2472-1654.100151

18. Keshk LI, Qalawa SA, Ibrahim NA. Effectiveness of an educational programme regarding nursing process on acquiring advanced skills among internship nursing students. Inter J Nurs 2018:5(2):32-44. https://dol org/10.15640/ijn.v5n2a4

19. Ingadóttir B, Zoëga S. Role of patient education in postoperative pain management. Nurs Stand 2017;32(2). https:/ doi.org/10.7748/ns.2017.e10939

20. Salim NA, Joshua R, AbuBaker NA, Chehab F, Jose A. Effect of a nursing in-service education programme on nurses' knowledge and attitudes towards pain management in a governmental hospital in the United Arab Emirates: nurses knowledge and attitudes towards pain management in a governmental hospital in the United Arab Em
Experimental random assignment study. Dubai Med J 2019;2(4):146-152. https://doi.org/10.1159/000503560

21. Bhatia P, Sawlani H, Tarachandani R. A study to assess and develop injection administration skill in medical undergraduates of GMC, Bhopal. Inter J Comm Med Public Health 2019;6(1):390. https://doi.org/10.18203/2394-
und 6040.ijcmph20185278

Accepted 24 June 2020. 